\title{
Severe Ischemic Stroke in a Patients with Idiopathic Thrombocytopenic Purpura: A Case Report
}

\author{
Haluk GÜMÜş', Halim YILMAZ² \\ ${ }^{1}$ Clinic of Neurology, Konya Training and Research Hospital, Konya, Turkey \\ ${ }^{2}$ Clinic of Physical Medicine and Rehabilitation, Konya Training and Research Hospital, Konya, Turkey
}

\begin{abstract}
In idiopathic thrombocytopenic purpura (ITP), a quite prevalent autoimmune hematological disease, thrombocytopenia is observed because of platelet destruction caused by immunological mechanisms. ITP usually leads to bleeding. Nevertheless, ITP, although rarely observed, may lead to thrombotic complications, including ischemic stroke. The present case is a female patient with ITP who developed cerebral infarction due to thrombus in the left middle cerebral artery. Our report reveals that severe ischemic stroke as well as bleeding may be encountered while monitoring an ITP case.

Keywords: Idiopathic thrombocytopenic purpura, stroke, thrombocytopenia, thrombus
\end{abstract}

\section{Introduction}

Idiopathic thrombocytopenic purpura (ITP) is a quite prevalent autoimmune hematological disease. In ITP, antibodies bind to platelet-specific antigens, and antibody-bound platelets are removed from circulation by splenic macrophages. Consequently, they lead to thrombocytopenia and generally to bleeding diathesis $(1,2)$. Nevertheless, ITP, even rare, may lead to thrombotic complications, including ischemic stroke $(2,3)$. Herein, we reported a female case with ITP who developed cerebral infarction due to the thrombus in the middle cerebral artery (MCA).

\section{Case Report}

A 55-year-old female patient was admitted to the emergency room with the complaints of weakness in the right upper and lower extremities, inability to speak, and somnolence. On neurological examination, her conscious state was determined to be drowsy, articulation was totally aphasic, and she displayed right central facial asymmetry. The muscle strength revealed that right lower and upper extremities were totally plegic. She had 27 points on the National Institutes of Health Stroke Scale. With the suspicion of cerebrovascular syndrome, computed cranial tomography (CCT) was performed, and the result was unremarkable (Figure 1). Therefore, diffusion-weighted cranial magnetic resonance imaging was performed, and acute infarction was detected within the area supplied by the left MCA (Figure 2). On 3-dimensional time-of-flight image, left MCA was detected to be totally occluded (Figure 3). Results of posteroanterior lung graph and transcardiac and transesophageal echocardiography were unremarkable. Patient was admitted to the neurology intensive care unit (ICU). Because platelet count was found as $40,000 \mathrm{~mm}^{3}$

Address for Correspondence: Haluk Gümüş, MD, Konya Eğitim ve Araştırma Hastanesi, Nöroloji Kliniği, Konya, Türkiye.

Phone: +905057585817 E-mail: dr.halukgumus@gmail.com

Received: August 2013 Accepted: March 2014

(OCopyright 2015 by Turkish Society of Physical Medicine and Rehabilitation - Available online at www.ftrdergisi.com

Cite this article as:
Gümüș H, Yllmaz H. Severe Ischemic Stroke in a Patients with Idiopathic Thrombocytopenic Purpura: A Case Report. Turk J Phys Med Rehab 2015;61:171-4. 
on laboratory analyses, the patient was consulted with the hematology clinic. Her history revealed that the case had irregularly been followed up depending on ITP for three years. Protein $C$, protein S, antithrombin-3, and homocysteine levels were within the normal limits. Neither factor 5 leiden mutation nor methylene tetrahydrofolate reductase gene mutation were detected. Cholesterol level, thyroid function test, folic acid, $B_{12}$ level, fasting blood glucose, oral glucose tolerance test, and $\mathrm{HbA} 1 \mathrm{c}$ levels

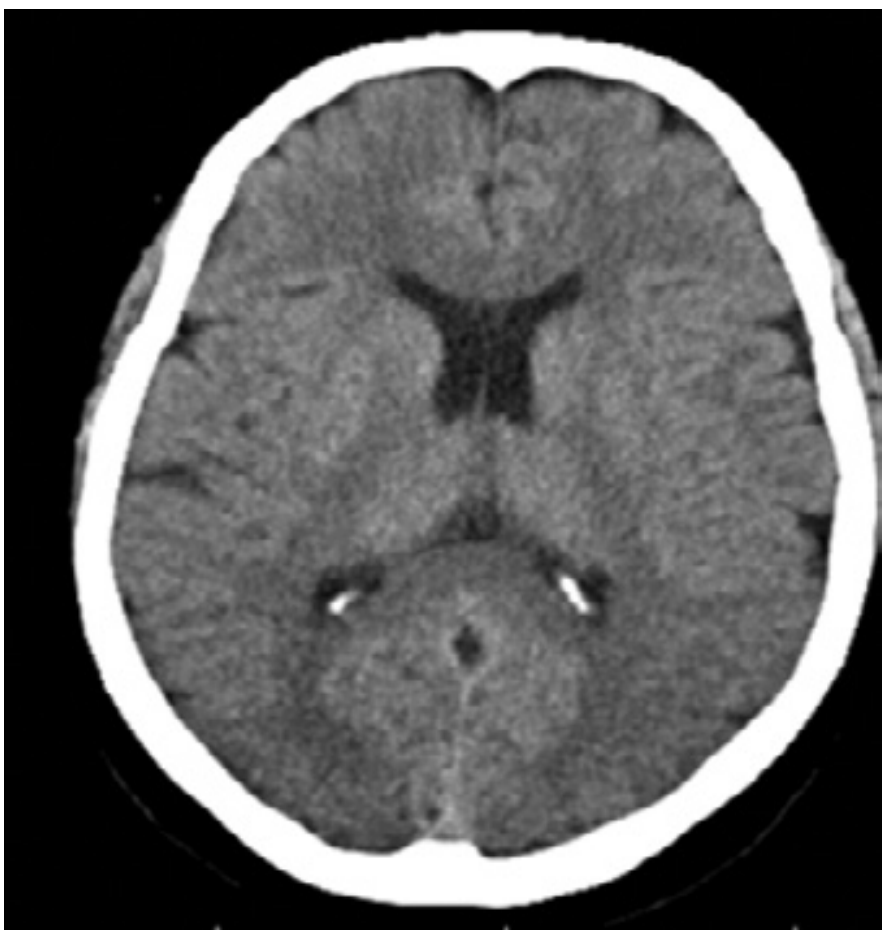

Figure 1. Cranial computer tomography: normal
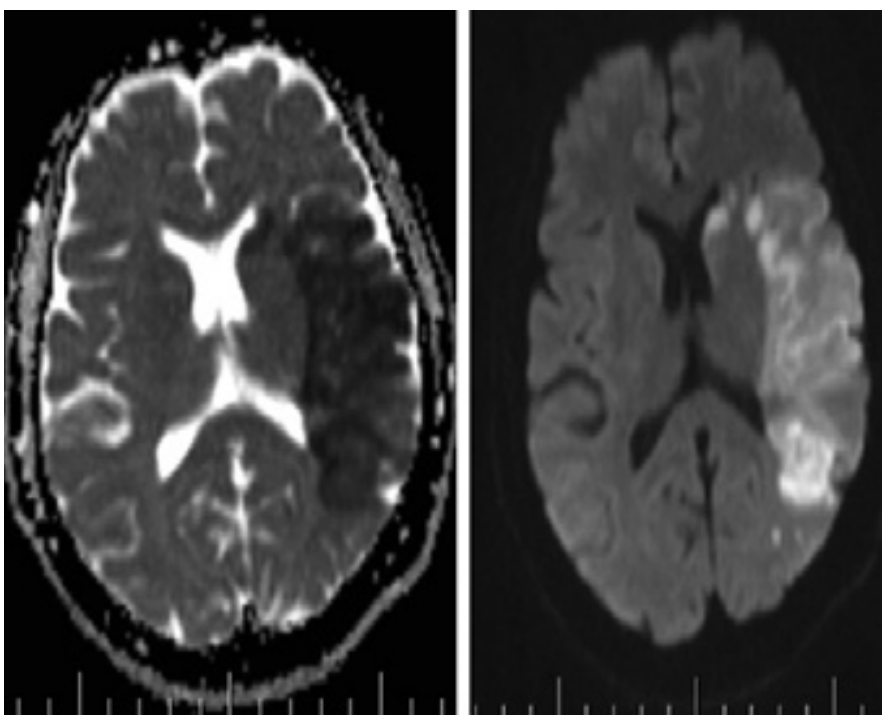

Figure 2. Diffusion magnetic resonance imaging and apparent diffusion coefficient imaging: restricted diffusion in the blood supply area of the left middle cerebral artery were normal. Vasculitic markers were found to be negative. The patient was administered with $1 \mathrm{mg} / \mathrm{kg}$ of methyl prednisolone. When thrombocyte level reached to $70,000 \mathrm{~mm}^{3}, 150 \mathrm{mg}$ of acetyl salicylic acid was commenced. For anti-edema, 20\% mannitol was administered. In addition, the patient was administered with amlodipine at a dose of $5 \mathrm{mg} /$ day because of mild arterial blood pressure elevation (arterial blood pressure, 140/90 $\mathrm{mmHg}$ ). When her blood pressure was under control, CCT was performed on day 15 of her hospital stay, and a hypodense area was observed in the left frontotemporoparietal region (Figure 4). The patient was transferred from ICU to the in-patient clinic on day 15 of follow-up. The patient was consulted with the physical medicine and rehabilitation department, and exercise program was recommended. No remarkable improvement was observed on week 4 of treatment. The patient was informed regarding the purpose of the study, and she gave written consent to participate.

\section{Discussion}

The present case is a female patient with ITP who developed cerebral infarction due to thrombus in the left MCA. Likewise, Mahawish et al. (4) reported a 79-year-old male case with weakness in the right side of the face and arm due to ITP. Rhee et al. (5) reported a 33-year-old male case with recurrent cerebral

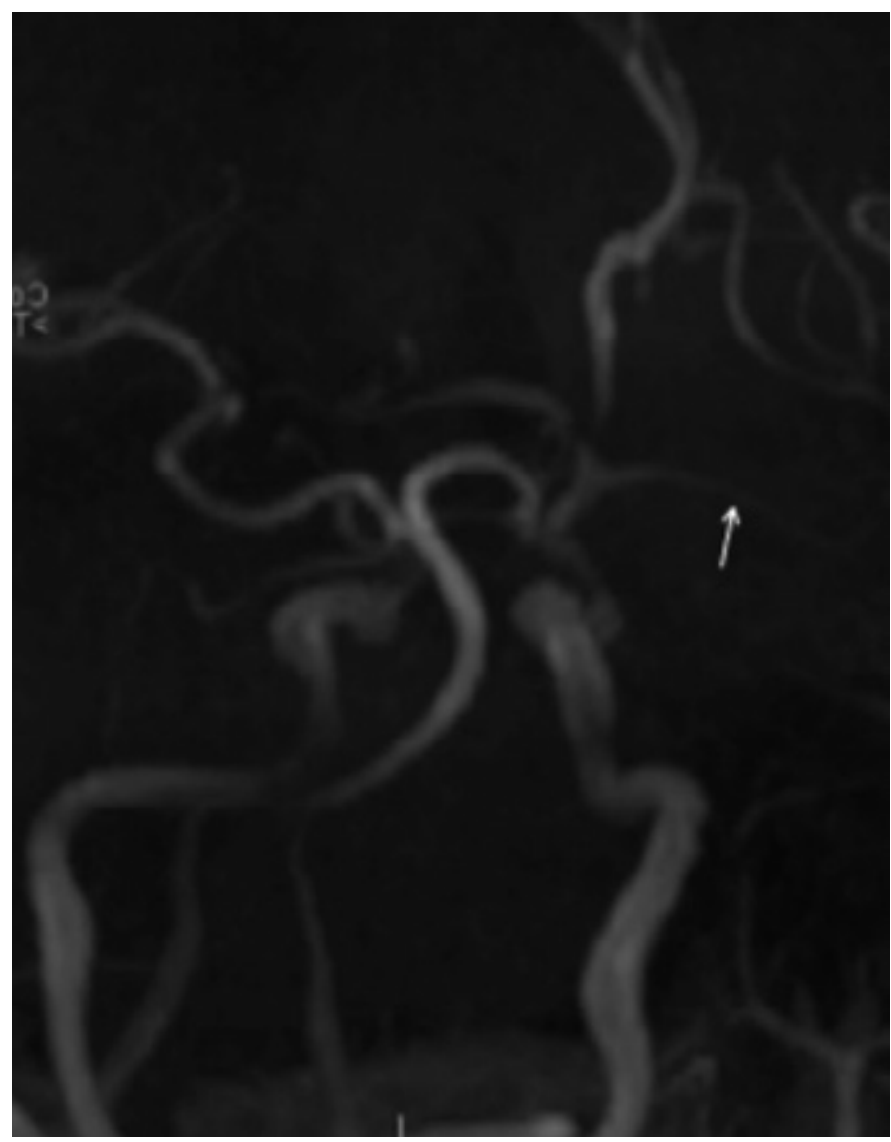

Figure 3. 3-D time-of-flight imaging: occluded image in the area supplied by the left MCA 


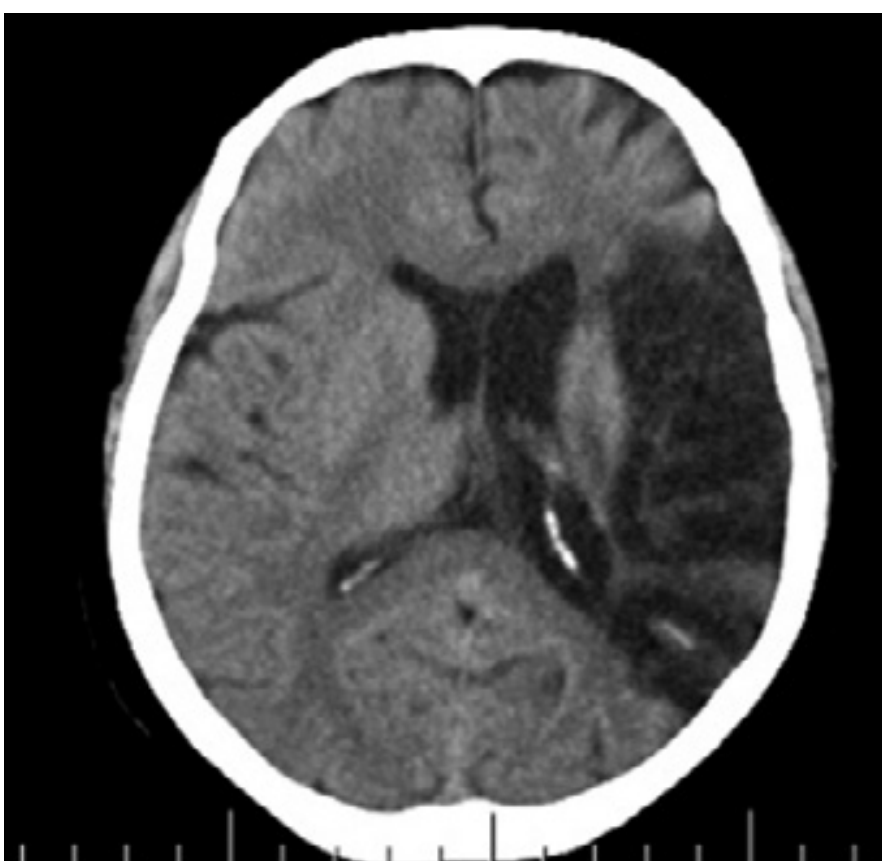

Figure 4. Cranial computer Tomography: hypodense area in the left frontotemporoparietal region

ischemic stroke stemming from ITP. Otsuki et al. (6) reported a female case with ITP and lupus anticoagulant with multiple ischemic infarctions. Theeler et al. (7) reported a 63-year-old male case with acute right occipital lobe infarction and acute left visual loss due to ITP.

In ITP, a quite prevalent autoimmune hematological disease, thrombocytopenia is observed because of platelet destruction caused by immunological mechanisms. Therefore, ITP usually leads to bleeding; however, although rare, it may cause thrombotic complications (5). Thrombotic complications in ITP may occur because of the disease itself after treatment modalities of ITP, such as splenectomy, IV immunoglobulin, danazol, and the association between ITP and other diseases such as antiphospholipid syndrome or thrombotic thrombocytopenic purpura (TTP) (5). Because the present case received no treatment for ITP or had neither antiphospholipid syndrome nor TTP, we considered that cerebral ischemic stroke resulting from MCA thrombus was caused by the disease itself. In this mechanism, humoral factors and platelet microparticles (PMPs) are released because of platelet destruction. PMPs induce thrombin activation and other coagulation factors (8). In ITP, circulating PMPs may enhance thrombotic events despite thrombocytopenia $(7,8)$. Rhee et al. (5) reported that antibodies directly influencing the antigens on both platelets and endothelial cells induce endothelial damage, thrombus formation, and embolic occlusion of the artery.

Treatment of acute ischemic stroke developing on the basis of ITP still remains controversial (7). The present patient had previously received no regular treatment for ITP. We rapidly increased the platelet levels using steroid and subsequently provided required efficacy by antiplatelet treatment. Nanri et al.
(8) reported that prednisolone stopped migraine and returned the platelet count to the normal levels in a 31-year-old ITP case, who had concomitant ischemic cerebral infarction and migraine with visual aura. Consistent with the study by Nanri et al. (8), platelet count returned to normal levels in the present case with prednisolone. Moreover, we initiated $5 \mathrm{mg}$ /day of amlodipine, a calcium channel blocker. In the literature, it has been reported that platelet fragmentation is a calcium-dependent process, and calcium channel blockers may hinder PMP release by inhibiting extracellular calcium influx $(9,10)$. On admission, the patient's right lower and upper extremities were flask, and she was aphasic. No alteration was observed in the post-treatment clinical status of our patient. We attributed this to the poor prognosis of MCA thrombus.

\section{Conclusion}

We consider that the treatment prevented the development of a new ischemic stroke attack and that the treatment of ischemic stroke in a patient with ITP should be individualized by taking the pathophysiological mechanism and hemorrhagic complications of stroke into consideration. Our report reveals that severe ischemic stroke and bleeding may be encountered while monitoring an ITP case.

Informed Consent: Written informed consent was obtained patient who participated in this case.

Peer-review: Externally peer-reviewed.

Author Contributions: Concept - H.G.; Design - H.Y.; Supervision - H.Y.; Resource - H.G.; Materials - H.G.; Data Collection and/or Processing - H.G.; Analysis and/or Interpretation - H.G.; Literature Review - H.Y.; Writer - H.G.; Critical Review - H.G.

Conflict of Interest: No conflict of interest was declared by the authors.

Financial Disclosure: The authors declared that this study has received no financial support.

\section{References}

1. McMillan R. The pathogenesis of chronic immune (idiopathic) thrombocytopenic purpura. Semin Hematol 2000;37:5-9. [CrossRef]

2. Ahn YS, Horstman LL. Idiopathic thrombocytopenic purpura: pathophysiology and management. Int J Hematol 2002;76:123-31. [CrossRef]

3. Arboix A, Besses C. Cerebrovascular disease as the initial clinical presentation of haematological disorders. Eur Neurol 1997;37:20711. [CrossRef]

4. Mahawish K, Pocock N, Mangarai S, Sharma A. Cerebral infarction in idiopathic thrombocytopenic purpura:a case report. BMJ Case Rep 2009;2009. pii: bcr04.2009.1748.

5. Rhee HY, Choi HY, Kim SB, Shin WC. Recurrent ischemic stroke in a patient with idiopathic thrombocytopenic purpura. J Thromb Thrombolysis 2010;30:229-32. [CrossRef]

6. Otsuki T, Funakawa T, Sugihara T, Kanzaki A, Wada H, Inoue T, et al. Multiple cerebral infarctions in a patient with refractory idio- 
pathic thrombocytopenic purpura. J Intern Med 1997;241:249-52. [CrossRef]

7. Theeler B, Ney JP. A Patient with idiopathic thrombocytopenic purpura presenting with an acute ischemic stroke. J Stroke Cerebrovasc Dis 2008;17:244-5. [CrossRef]

8. Nanri K, Niiyama K, Utsumi H, Sekine S, Katou H, Kougo K, et al. A case of migrainous infarction accompanying idiopathic thrombocytopenic purpura. Rinsho Shinkeigaku 2002;42:868-72.
9. Lee YJ, Jy W, Horstman LL, Janania J, Reyes Y, Kelley RE, et al. Elevated platelet microparticles in transient ischemic attacks, lacunar infarcts, and multi-infarct dementias. Thromb Res 1993;72:295-304. [CrossRef]

10. Jy W, Horstman LL, Arce M, Ahn YS. Clinical significance of platelet microparticles in autoimmune thrombocytopenias. J Lab Clin Med 1992;119:334-45. 